\title{
Clinical Features of Multiple Acyl-CoA Dehydrogenase Deficiency With ETFDH Variants in the First Korean Cases
}

\author{
Yoo Jinie Kim, M.D. ${ }^{1}$, Jung Min Ko $\mathbb{0}$, M.D., Ph.D. ${ }^{1}$, Junghan Song, M.D., Ph.D. ${ }^{2}$, and Kyung-A Lee, M.D., Ph.D. ${ }^{3}$ \\ ${ }^{1}$ Department of Pediatrics, Seoul National University College of Medicine, Seoul National University Children's Hospital, Seoul, Korea; ${ }^{2}$ Department of \\ Laboratory Medicine, Seoul National University College of Medicine, Seoul, Korea; ${ }^{3}$ Department of Laboratory Medicine, Yonsei University College of \\ Medicine, Seoul, Korea
}

\section{Dear Editor,}

Multiple acyl-CoA dehydrogenase deficiency (MADD; OMIM\# 231680) is an autosomal recessive fatty acid oxidation disorder [1]. Through the expanded newborn screening test (NST), its prevalence has been estimated to be 1 in 750,000-2,000,000 newborns [2]. MADD is divided into three clinical types [3]: the neonatal onset form with (type I) or without (type II) congenital anomalies [4], and the late-onset form (type III), which is often asymptomatic [5]. MADD is caused by defects in electron transfer flavoprotein (ETF) or electron transfer flavoprotein ubiquinone oxidoreductase (ETFDH) [6, 7]. Approximately 300 patients worldwide have been diagnosed as having MADD by genetic analysis, and 100 ETFDH mutations have been reported to date [8]. We report two MADD patients carrying novel, likely pathogenic variants, in ETFDH for the first time in Korea. Written informed consent was obtained from the patients' parents.

Patient 1 was a newborn boy who was transferred to the neonatal intensive care unit of our hospital on the sixth day of life, following onset of hypotonia, metabolic acidosis, hyperammonemia, and hypoglycemia 24 hours after birth. He was born fullterm with a weight of 3,650 g (50-90th percentile) to healthy, non-consanguineous parents. An older brother had died on the third day of birth due to undetermined causes. An older sister was typically developing and, thus far, without illness.

At the referring hospital, intravenous hydration with multivitamins was administered for a week with supplementation of Lcarnitine (300 mg/kg/day) and carglumic acid (100 mg/kg/day), but metabolic acidosis showed no improvement. When he first arrived at the hospital, he showed mild tachypnea and his anterior fontanel was large, but normotensive. He was hypotonic with an absent Moro reflex. A severe "sweaty feet" odor was noted. Laboratory tests revealed hyperammonemia $(153 \mu \mathrm{g} / \mathrm{dL}$; normal range, $15-51 \mu \mathrm{g} / \mathrm{dL}$ ) and metabolic acidosis ( $\mathrm{pH}, 7.250$; $\mathrm{HCO}_{3}-, 15.1 \mathrm{mmol} / \mathrm{L}$ ) without hypoglycemia. Tiny renal cysts were detected by ultrasonography, and hypoplastic bilateral temporal opercula were noticed on brain magnetic resonance images. Biventricular hypertrophy with normal contractility function was observed by echocardiography.

Acylcarnitine profiling by tandem mass spectrometry (TMS) and urine organic acid analysis suggested MADD type I (Table 1). A high dose of riboflavin (100 mg/day) was started immediately after obtaining the abnormal metabolic results, with a low-
Received: December 17, 2017

Revision received: February 20, 2018

Accepted: June 19, 2018

\section{Corresponding author: Jung Min Ko}

(D) https://orcid.org/0000-0002-0407-7828

Department of Pediatrics, Seoul National University College of Medicine, 101 Daehak-ro, Jongno-gu, Seoul 03080, Korea

Tel: +82-2-2072-3570, Fax: +82-2-743-3455, E-mail: jmko@snu.ac.kr

\section{(c) Korean Society for Laboratory Medicine}

This is an Open Access article distributed under the terms of the Creative Commons Attribution Non-Commercial License (http://creativecommons.org/licenses/by-nc/4.0) which permits unrestricted non-commercial use, distribution, and reproduction in any medium, provided the original work is properly cited. 
fat diet and L-carnitine supplementation (300 mg/kg/day). The ammonia level was nearly normal after continuous intravenous infusion of sodium benzoate $(250 \mathrm{mg} / \mathrm{kg} /$ day $)$, and the patient showed slightly increased muscle tone. However, metabolic acidosis persisted, and elevated C-reactive protein with decreased urine and distended abdomen implied the progress of sepsis. Antibiotics and an antifungal agent were administered to treat peritonitis and cellulitis on the abdominal wall. Respiratory sup- port was needed due to pulmonary edema. Even with antibiotics and inotropes, the patient died of sepsis with multiple organ failure 38 days after birth (Table 1 ).

Patient 2 was a boy born full-term with a weight of $3,480 \mathrm{~g}$ (10-50th percentile) to healthy, non-consanguineous parents. He had no symptoms at birth, but NST by TMS on the third day after birth showed elevated plasma acylcarnitines, suggesting MADD. Plasma acylcarnitine profile normalized on repeated

Table 1. Biochemical and genetic data of two male Korean patients with multiple acyl-CoA dehydrogenase deficiency

\begin{tabular}{|c|c|c|c|c|c|c|c|}
\hline No. Case & Subtype & $\begin{array}{l}\text { Age at } \\
\text { diagnosis }\end{array}$ & $\begin{array}{c}\text { Plasma acylcarnitine } \\
(\mu \mathrm{mol} / \mathrm{L})\end{array}$ & $\begin{array}{l}\text { Urine organic acid } \\
(\mathrm{mmol} / \mathrm{mol} \mathrm{Cr})\end{array}$ & Gene & $\begin{array}{c}\text { Genetic alteration } \\
\text { [zygosity] }\end{array}$ & $\begin{array}{l}\text { ACMG } \\
\text { category }\end{array}$ \\
\hline 1 & $\begin{array}{l}\text { Neonatal-onset with } \\
\text { congenital } \\
\text { anomalies (type I) }\end{array}$ & 12 days & $\begin{array}{l}\text { C4 } 9.95 \text { (cutoff, } 0.80 \text { ) } \\
\text { C5 } 12.66 \text { (cutoff, } 0.40 \text { ) }\end{array}$ & $\begin{array}{l}\text { Glutarate } 4223.55 \text { (cutoff, <3.0) } \\
\text { Ethylmalonate } 709.49 \text { (cutoff, }<6.5 \text { ) } \\
\text { 2-Hydroxyglutaric acid } 273.33 \text { (cutoff, }<69.5 \text { ) } \\
\text { Methyl-succinate } 194.74 \text { (cutoff, not detected) } \\
\text { Adipic acid } 118.41 \text { (cutoff, }<32.0 \text { ) } \\
\text { Isovalerylglycine } 63.70 \text { (cutoff, not detected) } \\
\text { Fumarate } 122.23 \text { (cutoff, }<14.0 \text { ) }\end{array}$ & ETFDH & $\begin{array}{l}\text { p.Arg452Gly [Het] } \\
\text { deletions exons 7-8 [Het] }\end{array}$ & $\begin{array}{l}L P \\
P\end{array}$ \\
\hline 2 & Late-onset (type III) & 7 days & $\begin{array}{l}\text { C6 } 0.24 \text { (cutoff, } 0.18 \text { ) } \\
\text { C8 } 0.62 \text { (cutoff, } 0.39 \text { ) } \\
\text { C10 } 0.63 \text { (cutoff, } 0.3 \text { ) }\end{array}$ & $\begin{array}{l}\text { Ethylmalonate } 39.81 \text { (cutoff, }<14.6 \text { ) } \\
\text { Adipic acid } 46.71 \text { (cutoff, }<34.3 \text { ) } \\
\text { Suberic acid } 35.54 \text { (cutoff, }<10.1 \text { ) } \\
\text { Sebacic acid } 23.96 \text { (cutoff, }<1.4 \text { ) }\end{array}$ & ETFDH & $\begin{array}{l}\text { c.831+3A > C [Het] } \\
\text { deletions exons } 1-7 \text { [Het] }\end{array}$ & $\begin{array}{l}L P \\
P\end{array}$ \\
\hline
\end{tabular}

Abbreviations: Het, heterozygote; LP, likely pathogenic; P, pathogenic; ACMG, American College of Medical Genetics and Genomics.

A $P$

Patient 1

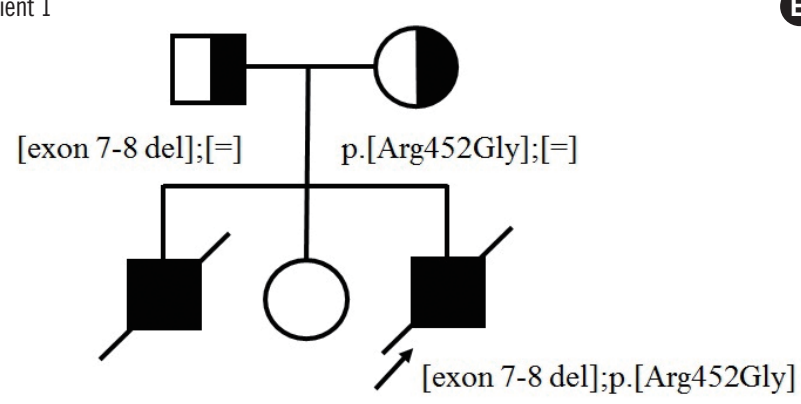

ETFDH quantitative PCR

Exon $7: 2^{\wedge}-\Delta \Delta$ Ct 0.349

Exon8: $2^{\wedge}-\Delta \Delta$ Ct 0.450

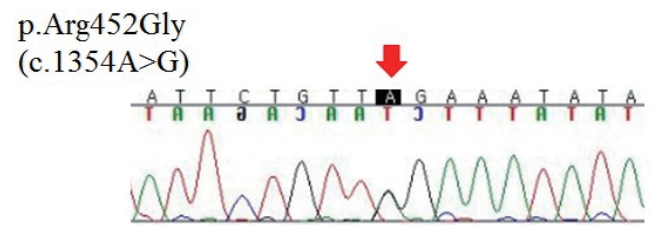

B

Patient 2

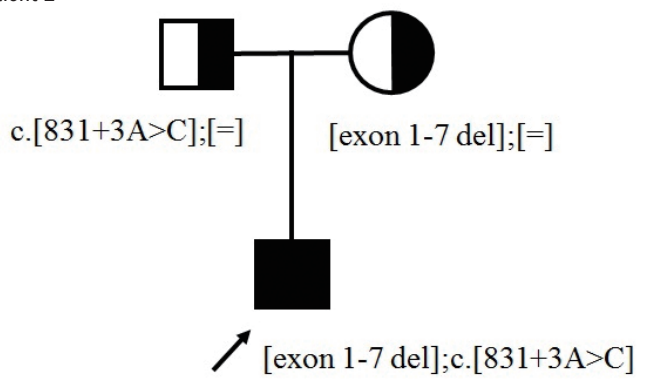

ETFDH quantitative PCR

Exon 1: $2^{\wedge}-\Delta \Delta$ Ct 0.3507

Exon3: $2^{\wedge}-\Delta \Delta \mathrm{Ct} 0.3965$

Exon5: $2^{\wedge}-\Delta \Delta \mathrm{Ct} 0.2413$

Exon $7: 2^{\wedge}-\Delta \Delta \mathrm{Ct} 0.6619$

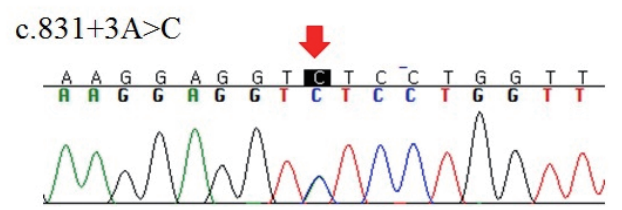

Fig. 1. Family pedigrees of two male Korean patients with multiple acyl-CoA dehydrogenase deficiency, carrying recessively inherited ETFDH variants. (A) Patient 1. (B) Patient 2. Affected and unaffected individuals are indicated by closed and open symbols, respectively. ETFDH alleles are represented by '[ =]' (wild-type), 'p.Arg452Gly (c.1354A>G)', 'c.831+3A >C'. Exon deletions and mutant alleles were identified by quantitative PCR and Sanger sequencing, respectively. 
testing, but urine glutarate increased slightly. Monitoring of urine organic acids after 8 hours of fasting by TMS revealed mildly elevated blood C6, C8, and C10, and increased urinary metabolites (Table 1). Based on these findings, a low-fat diet supplemented with medium-chain triglyceride milk, L-carnitine (100 $\mathrm{mg} / \mathrm{kg} /$ day), and riboflavin (100 mg/day) was initiated at the age of four months.

Following treatment initiation, plasma acylcarnitines normalized, and urinary ethylmalonate decreased. The patient is currently 24 months old. He has normal height (50-75th percentile) and weight (25-50th percentile), and is achieving normal developmental milestones.

For genetic diagnosis, we first sequenced ETFA, ETFB, and $E T F D H$, and identified one variant of ETFDH in each patient: c.1354A>G (p.Arg452Gly) for Patient 1 and c.831+3A >C for Patient 2 (Table 1). We investigated the other allele using quantitative (q)PCR to identify exon deletions. We used genomic DNA from two normal infants as controls, and GPCR was run in triplicate using 13 primer pairs for each exon. Data were analyzed by the $2^{-\Delta \Delta C t}$ method [9], and mean values are presented. Patient 1 had exon 7-8 deletion, and Patient 2 had multiple deletions in exons 1-7 (Fig. 1). Both parents of each patient were heterozygous carriers of each variant detected in their offspring; they were molecularly confirmed as compound heterozygotes with c.1354A>G (p.Arg452Gly) and exon 7-8 deletion for Patient 1 , and with c.831+3A>C and exon 1-7 deletion for Patient 2. The two sequence variants were absent from population databases, located in highly conserved regions, and considered damaging to protein function or structure by in-silico prediction. The variants were in trans with the other exon deletions in each patient as indicated by parental analyses. Therefore, p.Arg452Gly and c.831+3A >C could be classified as likely pathogenic according to the 2015 American College of Medical Genetics and Genomics standards/guidelines [10] (Fig. 1).

Early diagnosis and immediate treatment during the neonatal period determines the outcome in MADD. Expanded NST has increased the detection rate; however, accurate diagnosis may not be achieved with biochemical profiling alone. Thus, genetic analysis is likely necessary for either confirmative diagnosis or exclusion.

\section{Authors' Disclosures of Potential Conflicts of Interest}

The authors claim that there are no conflicts of interest.

\section{Acknowledgment}

We are grateful to the patients and their parents for their participation in this study. This study was supported by a grant from the Korean Health Technology R\&D Project, Ministry of Health \& Welfare, Korea (A120030).

\section{REFERENCES}

1. Przyrembel H, Wendel U, Becker K, Bremer HJ, Bruinvis L, Ketting D, et al. Glutaric aciduria type II: report on a previously undescribed metabolic disorder. Clin Chim Acta 1976:66:227-39.

2. Lindner M, Hoffmann GF, Matern D. Newborn screening for disorders of fatty-acid oxidation: experience and recommendations from an expert meeting. J Inherit Metab Dis 2010;33:521-6.

3. Grünert SC. Clinical and genetical heterogeneity of late-onset multiple acyl-coenzyme A dehydrogenase deficiency. Orphanet J Rare Dis 2014; 9:117.

4. Lehnert W, Wendel U, Lindenmaier S, Böhm N. Multiple acyl-CoA dehydrogenation deficiency (glutaric aciduria type II), congenital polycystic kidneys, and symmetric warty dysplasia of the cerebral cortex in two brothers. Europ J Pediat 1982;139:56-9.

5. Al-Essa MA, Rashed MS, Bakheet SM, Patay ZJ, Ozand PT. Glutaric aciduria type II: observations in seven patients with neonatal- and lateonset disease. J Perinatol 2000;2:120-8.

6. Olsen RK, Olpin SE, Andresen BS, Miedzybrodzka ZH, Pourfarzam M, Merinero B, et al. ETFDH mutations as a major cause of riboflavin-responsive multiple acyl-CoA dehydrogenation deficiency. Brain 2007; 130:2045-54.

7. Chen M, Peng J, Wei W, Wang R, Xu H, Liu H. A novel ETFDH mutation in an adult patient with late-onset riboflavin-responsive multiple acylCoA dehydrogenase deficiency. Int J Neurosci 2018;128:291-4.

8. Yotsumoto Y, Hasegawa Y, Fukuda S, Kobayashi H, Endo M, Fukao T, et al. Clinical and molecular investigations of Japanese cases of glutaric acidemia type 2. Mol Genet Metab 2008;94:61-7.

9. Livak KJ and Schmittgen TD. Analysis of relative gene expression data using real-time quantitative PCR and the 2(-Delta Delta $\mathrm{C}(\mathrm{T})$ ) method. Methods 2001:402-8.

10. Richards S, Aziz N, Bale S, Bick D, Das S, Gastier-Foster J, et al. Standards and guidelines for the interpretation of sequence variants: a joint consensus recommendation of the American College of Medical Genetics and Genomics and the Association for Molecular Pathology. Genet Med 2015;17:405-24. 